OPEN ACCESS

Edited by:

Megan A. McCrory,

Boston University, United States

Reviewed by:

Claudio Esteban Perez-Leighton,

Pontificia Universidad Católica de

Chile, Chile

Hollie Raynor

The University of Tennessee, Knoxville,

United States

*Correspondence:

Sruthi Vallur

vall0161@umn.edu

Specialty section:

This article was submitted to

Nutrition Methodology,

a section of the journal

Frontiers in Nutrition

Received: 13 July 2020

Accepted: 16 September 2020

Published: 22 October 2020

Citation:

Valluri $S$, French $S A$, Elbel $B$,

Oakes JM, Rydell SA and Harnack LJ

(2020) Within- and

Between-Household Variation in Food

Expenditures Among Low-Income

Households Using a Novel Simple

Annotated Receipt Method.

Front. Nutr. 7:582999.

doi: 10.3389/fnut.2020.582999

\section{Within- and Between-Household Variation in Food Expenditures Among Low-Income Households Using a Novel Simple Annotated Receipt Method}

\author{
Sruthi Valluri ${ }^{1,2 *}$, Simone A. French ${ }^{1}$, Brian Elbel ${ }^{3}$, J. Michael Oakes ${ }^{1}$, Sarah A. Rydell ${ }^{1}$ and \\ Lisa J. Harnack ${ }^{1}$ \\ 1 Division of Epidemiology and Community Health, School of Public Health, University of Minnesota, Minneapolis, MN, \\ United States, ${ }^{2}$ Medical Scientist Training Program, University of Minnesota Medical School, Minneapolis, MN, \\ United States, ${ }^{3}$ School of Medicine and Wagner School of Public Service, New York University, New York, NY, United States
}

Background: Household food purchasing behavior has gained interest as an intervention to improve nutrition and nutrition-associated outcomes. However, evaluating food expenditures is challenging in epidemiological studies. Assessment methods that are both valid and feasible for use among diverse, low-income populations are needed. We therefore developed a novel simple annotated receipt method to assess household food purchasing. First, we describe and evaluate the extent to which the method captures food purchasing information. We then evaluate within- and between-household variation in weekly food purchasing to determine sample sizes and the number of weeks of data needed to measure household food purchasing with adequate precision.

Methods: Four weeks of food purchase receipt data were collected from 260 low-income households in the Minneapolis-St. Paul metropolitan area. The proportion of receipt line items that could not be coded into one of 11 food categories (unidentified) was calculated, and a zero-inflated negative binomial regression was used to evaluate the association between unidentified receipt items and participant characteristics and store type. Within- and between-household coefficients of variation were calculated for total food expenditures and several food categories.

Results: A low proportion of receipt line items (1.6\%) could not be coded into a food category and the incidence of unidentified items did not appreciably vary by participant characteristics. Weekly expenditures on foods high in added sugar had higher within- and between-household coefficients of variation than weekly fruit and vegetable expenditures. To estimate mean weekly food expenditures within $20 \%$ of the group's usual ("true") expenditures, 72 households were required. Nine weeks of data were required to achieve an $r=0.90$ between observed and usual weekly food expenditures.

Conclusions: The simple annotated receipt method may be a feasible tool for use in assessing food expenditures of low-income, diverse populations. Within- and 
between-household coefficients of variation suggest that the number of weeks of data or group sizes required to precisely estimate usual household expenditures is higher for foods high in added sugar compared to fruits and vegetables.

Keywords: nutrition methodologies, household food purchasing, food receipt method, within-household variation, between-household variation, epidemiology

\section{BACKGROUND}

Food purchasing behavior has gained interest as an intervention target to improve nutrition and nutrition-associated health outcomes in the United States (1-4). Evidence that the nutritional quality of food purchases corresponds with dietary quality $(5,6)$ has prompted numerous interventions targeting food purchasing behavior $(3,4)$. Low-income populations have generated particular attention due to socioeconomic differences in diet quality $(7,8)$. However, valid and feasible methods for measuring food purchasing among low-income households are limited.

Existing methods to evaluate household food purchasing behavior-including home food inventories (9-12), bar code scanners $(13,14)$, point of sale data $(15-17)$, food purchase records (18-21), and food receipts (22-25)-have unique strengths, but their weaknesses present noteworthy challenges for implementation, validity, and capturing the full range of purchase information (Table 1) (12). Furthermore, there are important differences in food purchasing by household socioeconomic status $(7,8)$. Assessments methods therefore need to be evaluated among low-income households to ensure that the detail and variation in household expenditures is fully captured (12).

Food receipt methods are appealing because they can be used to assess food expenditures from a variety of retailers and for all types of foods $(12,22-25)$. In the annotated food receipt method, participants collect receipts and transcribe information onto forms to clarify missing details and unclear abbreviations (e.g., items described as "dairy" rather than "skim milk," or "Pillsbury white cake mix" listed as "pills white") (24, 25). However, participant burden is high and literacy is required. In contrast, participants submit receipts without transcription or annotation in the food receipt collection method (22). Although this method substantially lowers participant burden, many details that receipts generally lack may not be captured.

To capitalize on the detailed information possible using the annotated food receipt method while reducing participant burden, a simple version of the annotated food receipt method (the "simple annotated receipt method") was developed for use in a prospective trial (26). Participants are not required to transcribe all purchase information using this newly developed method; instead, they annotate items with vague or unclear descriptions directly on the receipts.

This study has two primary aims. First, we describe and evaluate the simple annotated receipt method using data from the aforementioned trial. We illustrate the food purchasing information that may be captured using this method. We also evaluate the extent to which receipt items could not be identified due to inadequate annotation and whether this varies by participant characteristic and store type. To date, this is the first study to describe and evaluate this method.

Second, we evaluate sources of variation in household food purchasing to help guide study designs using this method. Household food purchasing behavior is often evaluated for one of three research objectives: (1) to compare mean household expenditures between different groups (e.g., control vs. intervention groups), (2) to rank households by expenditures (e.g., into quartiles), (3) or to assess an individual household's expenditures (e.g., change in expenditures before and after intervention) $(27,28)$. Thus, this paper addresses practical and essential questions: How many households are needed in a study group to assess the group's usual ("true") food expenditure pattern or to rank households with reasonable precision? How many weeks of data are needed to precisely evaluate a household's usual food expenditure?

Evaluating a household's usual expenditures requires an understanding of the sources of variation in week-to-week spending. Similar to dietary intake-which varies daily and requires multiple days of assessment-household food expenditures likely vary from week to week, necessitating multiple weeks and adequate sample sizes to ascertain usual food expenditures $(28,29)$. Group sizes and data collection periods may also vary by food group, analogous to the differing number of dietary assessments needed to evaluate intake of specific nutrients (28).

We quantify within- and between-household variation in weekly expenditures for all foods and beverages and for two specific categories of food: fruits and vegetables, and foods high in added sugar (sugar-sweetened beverages [SSBs], candy, and sweet baked goods). Using these values, we estimate the group size needed to estimate a group's average food expenditures. We also estimate the number of weeks of data needed to rank household expenditures or estimate a household's usual food expenditures with adequate precision. Results from this paper can help researchers design efficient studies of food purchasing behavior (27-29). To our knowledge, this is the first study to provide these important metrics.

\section{MATERIALS AND METHODS}

\section{Study Population}

This paper is a secondary analysis of data from a prospective trial $(26,30,31)$. Briefly, low-income households in the Minneapolis-St. Paul, Minnesota, metropolitan area were recruited between August 2013 and May 2015. Eligibility criteria included: (1) not currently enrolled in the Supplemental Nutrition Assistance Program (SNAP) or planning to enroll 
TABLE 1 | Description and summary of strengths and weaknesses of existing methods to assess household food purchasing

\begin{tabular}{|c|c|c|c|}
\hline Method & Description & Strengths & Limitations \\
\hline $\begin{array}{l}\text { Home food inventories } \\
(9-12)\end{array}$ & $\begin{array}{l}\text { Collected by study staff or } \\
\text { participants. Catalogs foods available } \\
\text { in the home at the time inventory is } \\
\text { completed }\end{array}$ & $\begin{array}{l}\text { - Low participant burden } \\
\text { - Relatively easy to complete }\end{array}$ & $\begin{array}{l}\text { - Multiple administrations of the inventory } \\
\text { required for accurate assessment of usual } \\
\text { household food available } \\
\text { - Foods purchased and consumed outside } \\
\text { home are not ascertained } \\
\text { - Captures types of food (e.g., soft drinks) but } \\
\text { not quantity (e.g., fluid ounces) }\end{array}$ \\
\hline $\begin{array}{l}\text { Bar code scanners } \\
(12-14)\end{array}$ & $\begin{array}{l}\text { Participants scan bar codes for all } \\
\text { foods purchased. Researchers } \\
\text { provide codes to participants for } \\
\text { unpackaged items. }\end{array}$ & $\begin{array}{l}\text { - Does not require participant literacy } \\
\text { - Can provide rich data on types and } \\
\text { quantities of packaged foods }\end{array}$ & $\begin{array}{l}\text { - Scanners can be expensive, susceptible to } \\
\text { hardware malfunctioning, and rely on external } \\
\text { database of codes to match bar codes to } \\
\text { food items. } \\
\text { - May not capture foods that typically lack bar } \\
\text { codes such as bulk items, fresh produce and } \\
\text { meats in grocery stores, and food purchased } \\
\text { at restaurants. }\end{array}$ \\
\hline $\begin{array}{l}\text { Point of sale data } \\
(12,15-17)\end{array}$ & $\begin{array}{l}\text { Uses data available from food retailers } \\
\text { on customer food purchasing }\end{array}$ & $\begin{array}{l}\text { - Minimal participant burden } \\
\text { - Can provide rich data on types and } \\
\text { quantities of foods }\end{array}$ & $\begin{array}{l}\text { - Linking data from vendors with individual } \\
\text { shoppers can be challenging due to } \\
\text { proprietary nature of data, privacy concerns, } \\
\text { and technological issues } \\
\text { - Unable to capture comprehensive } \\
\text { assessment of household food purchases } \\
\text { since it is generally limited to one retailer }\end{array}$ \\
\hline $\begin{array}{l}\text { Food purchase record } \\
(12,17-21)\end{array}$ & $\begin{array}{l}\text { Participants keep a written record of } \\
\text { all foods purchased, including } \\
\text { description of each item and quantity. }\end{array}$ & $\begin{array}{l}\text { - Offers detailed and comprehensive } \\
\text { information about types and quantities of } \\
\text { food purchased over time }\end{array}$ & $\begin{array}{l}\text { - Requires participant literacy } \\
\text { - High participant burden }\end{array}$ \\
\hline $\begin{array}{l}\text { Food receipt collection } \\
(12,22,23)\end{array}$ & $\begin{array}{l}\text { Participants collect and mail all } \\
\text { receipts for food purchases. Receipt } \\
\text { purchases are coded by study staff. }\end{array}$ & $\begin{array}{l}\text { - Offers details about expenditures over time } \\
\text { - Low participant burden }\end{array}$ & $\begin{array}{l}\text { - May not be able to code purchases with } \\
\text { insufficient detail on receipt, including } \\
\text { specific types of food (e.g., "produce" vs. } \\
\text { "tomatoes") and quantities (e.g., fluid ounces) }\end{array}$ \\
\hline $\begin{array}{l}\text { Annotated food receipt } \\
(12,24,25)\end{array}$ & $\begin{array}{l}\text { Participants collect receipts for food } \\
\text { purchases and transcribe receipt } \\
\text { information onto a form to provide } \\
\text { details not available on receipts }\end{array}$ & $\begin{array}{l}\text { - Offers detailed information about all food } \\
\text { and beverage purchases }\end{array}$ & $\begin{array}{l}\text { - Requires participant literacy } \\
\text { - High participant burden }\end{array}$ \\
\hline
\end{tabular}

during the study; (2) household income $<200 \%$ the federal poverty rate or participating in a government program that automatically qualifies households for SNAP (e.g., the Diversionary Work Program in Minnesota); (3) adult in the household primarily responsible for food shopping is able to read and speak English and participate in the study. Some SNAP eligibility criteria, such as citizenship status, were not applied. The University of Minnesota Institutional Review Board approved all aspects of the study (ClinicalTrials.gov: NCT02643576).

Participants were asked to annotate and submit all household food purchase receipts throughout the study using the protocol described in greater detail below. At the baseline visit, participants completed a survey to assess demographic characteristics. Household food security was evaluated using the US Household Food Security Survey Module: 6 Item Short Form (32).

Participants who completed baseline measures and submitted at least 2 weeks of receipts received a study debit card with monthly benefits for 12 weeks. Households were randomized into one of four study arms, which varied with respect to whether a financial incentive was provided for fruit and vegetable purchases and whether foods high in added sugars could be purchased with benefits. Analyses for this paper are limited to the baseline period of the trial.

\section{Simple Annotated Receipt Method Receipt Collection}

Research staff met participants in-person to provide verbal and written instructions, and materials necessary for receipt collection. Participants were instructed to collect all food purchase receipts and to query other household members for receipts. Receipts were requested from both restaurants (retailers that serve or sell ready-to-consume food) and food retailers (retailers that primarily sell unprepared food). This paper focuses on receipts from food retailers.

Participants were instructed to annotate food retailer receipts if the item description was vague or unclear. To annotate receipts, participants were instructed to write details directly on the receipt next to the item lacking information. For example, an item described as "produce" would need annotation to specify the type of produce (e.g., "tomatoes"). Annotation was not requested for quantities of food purchased. Missing food receipt forms were requested for purchases without receipts, such as purchases made at retailers that do not provide receipts (e.g., farmer's market) or lost receipts. The missing receipt form included details such 
as the store name, date of purchase, food items purchased, quantity purchased, price per item, and total price. As part of the instruction process, study staff reviewed a sample annotated receipt and missing receipt form with participants.

All receipts were to be mailed to study staff on a weekly basis using pre-addressed, postage-paid envelopes, which were prelabeled with the participant ID number, dates comprising the week of receipt collection, and the target mailing date to facilitate tracking by staff. Participants were mailed a gift card as a reward for receipt collection every month. The reward amount was prorated, with $\$ 30$ provided if 4 weeks of receipts were submitted, and lesser amounts for three (\$15), two (\$10), and one (\$5) week. Research staff contacted participants to encourage submission if receipts were not received.

\section{Food Retailer Receipt Coding}

Receipts were first sorted into two categories: restaurant purchases and food retailer purchases. Restaurants were classified as full-service, limited-service, or unable to determine restaurant type. This study focuses on food retailers, which were further classified as supermarket/market (e.g., Cub, Aldi, farmers market), natural food store (e.g., co-ops), warehouse store (e.g., Costco, Sam's Club), drug store (Walgreens, CVS), convenience store/gas station (including dollar stores), superstore (e.g., Target, Walmart), or other (e.g., Home Depot, Menards) (24). Each receipt was then assigned a unique identifier to specify the participant, week, and receipt number.

Items on food retailer receipts were classified into one of 11 food categories. The choice of food categories reflects the primary aims of the original trial, which was to evaluate two food categories: fruits and vegetables, and foods high in added sugars (sugar-sweetened beverages [SSBs], sweet baked goods, and candies). Items with potential substitution effects (e.g., milk, savory snacks) were measured, while items of lesser interest to the trial (e.g., diet sodas) were categorized as "other food" purchases.

Food items that lacked sufficient detail to code into one of the 11 food categories were coded as having "insufficient detail to code" (unidentified). Before coding an item as unidentified, study staff followed a series of procedures to obtain missing information. First, an online search was conducted using the store name, item, code, and/or abbreviation. When available, the item's Universal Product Codes was searched (http://www. upcdatabase.org). Stores were contacted to verify the item for successful online searches. If these procedures failed to provide necessary details, items were coded as unidentified.

For each receipt, the total number of line items and expenditures were calculated for overall food and beverages, and for each of the food categories. Totals for each category were determined by summing across line items classified into the category. Quantities or weight of foods purchased was not considered in the tabulation. For example, a line item of "apples" would count as a frequency of one in the tally for receipt items for fruits, and total expenditure amounts are reported rather than per unit prices. The first 10 receipts coded were reviewed for accuracy by a second staff member. Errors identified were reviewed and corrected.
Spot checks of coded receipts were conducted throughout for quality assurance.

\section{Statistical Analysis}

Analyses for this paper are restricted to participants who submitted at least 3 weeks of food retailer receipts during the 4-week baseline period. First, we described the food purchasing information captured by the method using total number of receipt line items and expenditures for overall food expenditures, each of the 11 food categories, and items categorized as having insufficient detail to code (unidentified). Food purchasing data was also evaluated by store, which was collapsed into four types based on previous literature and low frequency of receipts in some categories: Grocery stores, Convenience stores/Gas Stations, Drug stores, and Superstores/Mass merchandiser/Warehouse club store.

Second, we used a zero-inflated negative binomial model to evaluate whether unidentified line items on receipts were associated with participant characteristic or store type. This model was used because the distribution of unidentifed items was heavily skewed, with $94 \%$ of receipts submitted without any unidentified items. Likelihood ratio tests confirmed zeroinflation and overdispersion, supporting the model choice. The model simultaneously evaluates two processes. The logit portion of the model evaluates participant characteristics and store types associated with submitting receipts with unidentified items, yielding odds ratios (OR). The negative binomial model evaluates the incident rate ratios (IRR) of unidentified items by participant characteristics and store types among those who submitted at least one receipt with an unidentified item. Participant characteristics of interest were age, gender, race/ethnicity, marital status, household size, education level, annual household income, and food security. A dummy variable was used to indicate the store type. The model was adjusted for the total number of line items per receipt. A $p<0.05$ was the criterion for claiming statistical significance.

Third, a mixed effects regression model with an unstructured covariance and restricted maximum likelihood estimator was used to estimate the mean, within-household variance $\left(\sigma_{w}^{2}\right)$, and between-household $\left(\sigma_{b}^{2}\right)$ variance for overall food expenditures, fruits and vegetables, and foods high in added sugar. We calculated within- and between-household coefficients of variation $\left(\mathrm{CV}_{\mathrm{w}}\right.$ and $\mathrm{CV}_{\mathrm{b}}$, respectively) as percentages using the following equations (29): $C V_{w}=\left(\sigma_{w} /\right.$ mean $) \times 100$; $C V_{b}=\left(\sigma_{b} /\right.$ mean $) \times 100$. The ratio of within- to betweenhousehold variation, the variance ratios, were calculated as $\sigma_{w}^{2}$ $/ \sigma_{b}^{2}$ (which is equivalent to $\left[C V_{w} / C V_{b}\right]^{2}$ ).

Using these values, we calculated the group size or weeks of data needed to estimate usual (or "true") food expenditures with adequate precision. The usual household food expenditures refers to the hypothetical "true" average of the study sample about which a household's expenditures vary during the period of data collection. We assume that within- and between-household variation observed in our sample is due to random variation 
TABLE 2 | Baseline characteristics of households using the simple annotated receipt method as part of a trial evaluating food purchasing behavior $(n=260)$.

\begin{tabular}{|c|c|}
\hline Characteristic & $N(\%)$ \\
\hline \multicolumn{2}{|l|}{ AGE, YEARS } \\
\hline Under 25 & $14(5.4)$ \\
\hline $25-44$ & $115(44.2)$ \\
\hline $45-64$ & $113(43.5)$ \\
\hline Over 65 & $18(6.9)$ \\
\hline \multicolumn{2}{|l|}{ GENDER } \\
\hline Male & 48 (18.5) \\
\hline Female & $212(81.5)$ \\
\hline \multicolumn{2}{|l|}{ RACE/ETHNICITY } \\
\hline White, Non-Hispanic & 77 (29.6) \\
\hline Black, Non-Hispanic & $131(50.4)$ \\
\hline Other, Hispanic & $52(20.0)$ \\
\hline \multicolumn{2}{|l|}{ MARITAL STATUS } \\
\hline Single, never married & $117(45.2)$ \\
\hline Married or partnered & $72(27.8)$ \\
\hline Separated/divorced/widowed & $70(27.0)$ \\
\hline \multicolumn{2}{|l|}{ HOUSEHOLD SIZE } \\
\hline 1 person & 58 (22.3) \\
\hline 2 people & $58(22.3)$ \\
\hline 3 people & $61(23.5)$ \\
\hline 4 or more people & $83(31.9)$ \\
\hline \multicolumn{2}{|l|}{ EDUCATION LEVEL } \\
\hline High school graduate or less & $75(28.9)$ \\
\hline Some college/associates degree & $138(53.1)$ \\
\hline College graduate or higher & $47(18.1)$ \\
\hline \multicolumn{2}{|l|}{ ANNUAL HOUSEHOLD INCOME } \\
\hline$\$ 14,999$ or less & 79 (33.2) \\
\hline$\$ 15,000-\$ 34,999$ & $114(47.9)$ \\
\hline$\$ 35,000$ or more & $45(18.9)$ \\
\hline \multicolumn{2}{|c|}{ HOUSEHOLD FOOD SECURITY STATUS } \\
\hline High or marginal & $53(19.3)$ \\
\hline Low & $96(34.9)$ \\
\hline Very low & $126(45.8)$ \\
\hline
\end{tabular}

about the hypothetical average, and not due to a changes in habitual spending patterns (33).

The number of households in a group $\left(n_{g}\right)$ required to estimate group mean expenditure using a single week of expenditure data was calculated as follows: $n_{g}=Z_{\alpha}^{2} \times\left[\left(C V_{b}^{2}+C V_{w}^{2}\right) / D_{0}^{2}\right]$, where $\mathrm{D}_{0}$ is a specified percentage deviation of the group's usual expenditure, and $Z_{\alpha}$ is the normal deviate for the percentage of times the measured expenditure should be within a specified limit (29). For the purposes of this study, we evaluated estimates with $95 \%$ CIs (i.e., $Z_{\alpha}=1.96$ ), with $D_{0}$ varying between 10 and $50 \%$. The number of weeks of expenditure data $\left(\mathrm{n}_{\mathrm{r}}\right)$ needed to obtain a given Pearson correlation coefficient, $r$, between observed and unobserved usual expenditures was also calculated $(27,33)$. The equation is as follows: $n_{r}=r^{2} /\left(1-r^{2}\right) \times\left(\sigma_{w}^{2} / \sigma_{b}^{2}\right)$, where $r$ varied between 0.75 and 0.95 . Finally, the number of weeks of expenditure data $\left(\mathrm{n}_{\mathrm{w}}\right)$ required to estimate mean household expenditures within the specified percentage deviation $\left(D_{0}\right)$ from the household's usual ("true") expenditure was calculated as follows (29): $n_{w}=\left(Z_{\alpha} \times C V_{w} / D_{0}\right)^{2} . \mathrm{D}_{0}$ varied between 10 and $50 \%$ and $Z_{\alpha}$ was fixed at 1.96 to derive $95 \%$ CIs.

\section{RESULTS}

Of the 279 participants enrolled in the study, 260 submitted at least 3 weeks of food receipts during the baseline period and were included in the analyses. Participant characteristics are presented in Table 2. To summarize, most participants were female, over half were African-American, and most reported low or very low food security.

\section{Food Purchase Information}

Over a 4-week period, households included in the analyses submitted a total of 5,635 receipts. Of these, 2,094 receipts from restaurants and 11 receipts for non-food purchases were excluded from analyses. Over $98 \%$ of the receipts were submitted as original receipts; $1.5 \%(n=52)$ were submitted as missing receipt forms. Over the 4-week data collection period, households submitted on average 13.6 receipts (95\% CI: 12.5, 14.7). This translates to 3.4 receipts per week (95\% CI: 3.1, 3.7), with an average of 8.3 (95\% CI: 7.6, 9.0) line items per receipt. On average, households spent \$23.30 (95\% CI: \$21.00, \$25.51) per receipt.

Figure 1 shows the average household food expenditures over a 4-week period for selected food categories. On average, unidentified items accounted for \$5.81 (95\% CI: \$4.25, \$7.37) of household food expenditures over the 4-week period. Fruit and vegetable expenditures accounted for \$15.41 (95\% CI: $\$ 13.04, \$ 17.77)$ and $\$ 16.34$ (\$13.90, \$18.78), respectively. Households spent an average of $\$ 13.45$ (95\% CI: $\$ 11.45$, $\$ 15.45$ ) on sugar-sweetened beverages (SSBs) over the 4 -week period. Table 3 presents average household food expenditures and line items submitted over a 4-week period for all categories of food. Foods coded as "other" -food and beverages that did not fit into the 11 food categories of interestcomprised the largest share of expenditures, accounting for $\$ 180.00$ (95\% CI: \$162.52, \$197.47) of food expenditures and 58.7 (95\% CI: 53.2, 64.2) receipt line items over a 4week period.

Figure 2 shows the average household food expenditures over a four-week period by store type. Households spent the most money at grocery stores (\$169.34, 95\% CI: \$150.37, \$188.30) and superstores/mass merchandisers/warehouse club stores $(\$ 115.68$, 95\% CI: \$98.89, \$132.46). Table 3 presents average household food expenditures and receipt line items submitted over a 4 -week period by different store types. Grocery stores and superstores accounted for the greatest number of line items submitted over the 4-week period, accounting for 62.4 (95\% CI: 55.5, 69.3) and 36.9 (95\% CI: $31.7,42.1)$ receipt line items, respectively.

Supplemental Tables 1, 2 describe the total volume of food expenditure information captured over the 4-week data collection period. The 3,530 food retailer receipts submitted by the study sample represented $\$ 70,822.21$ in 


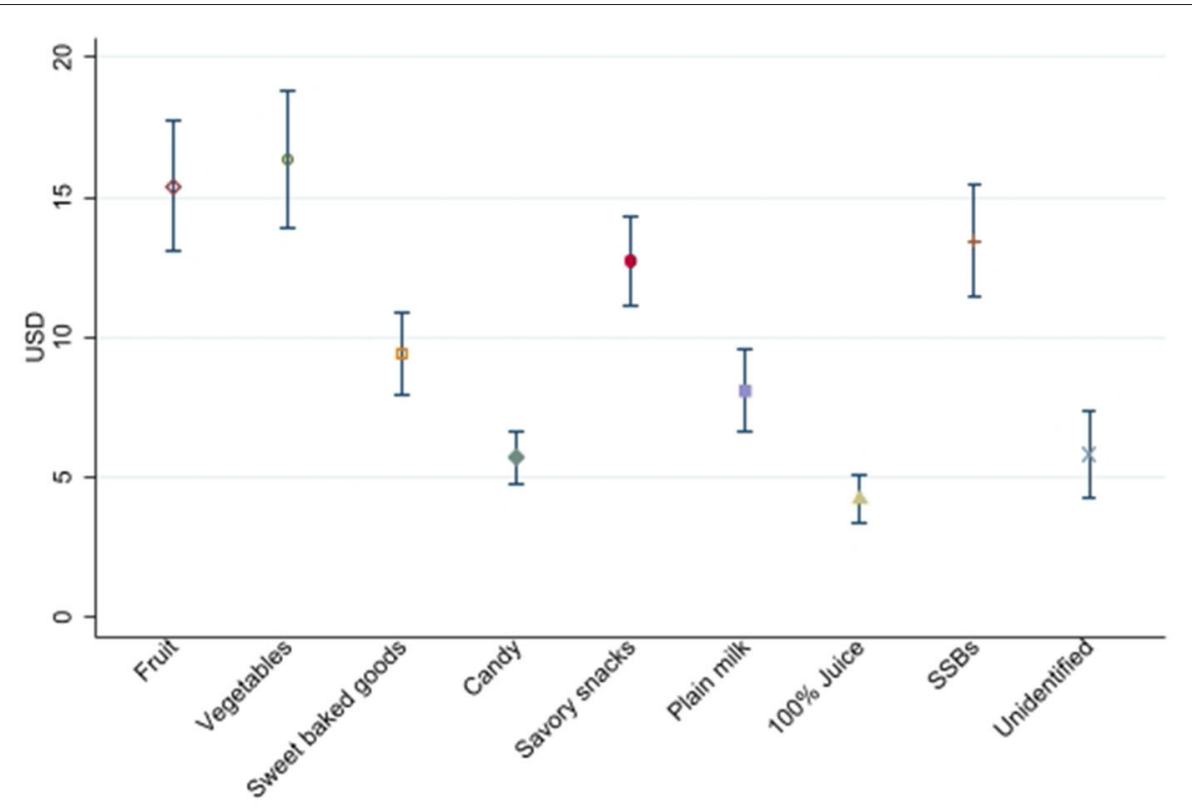

FIGURE 1 | Average household expenditures submitted over a 4-week period by low-income households using a simple annotated receipt method, for selected food categories $(n=260)$.

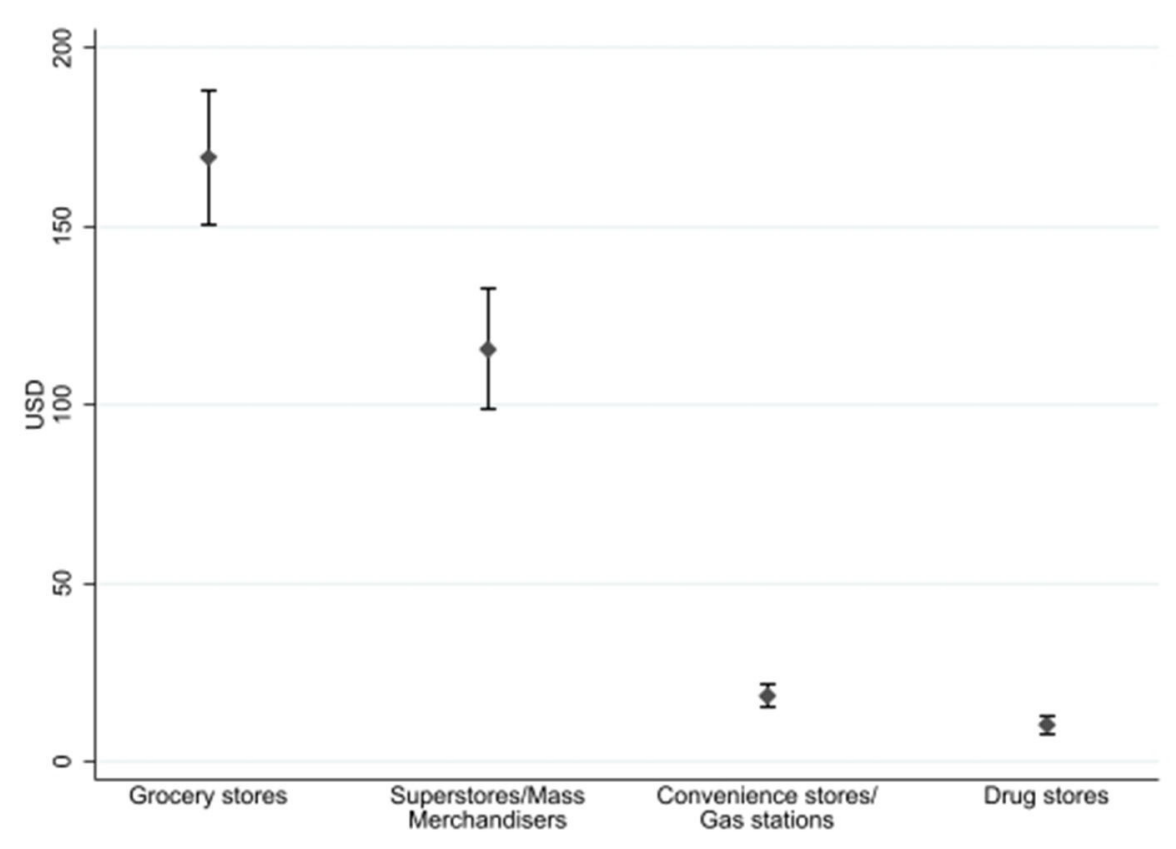

FIGURE 2 | Average household expenditures submitted over a 4-week period by low-income households using a simple annotated receipt method, by store type $(n=260)$.

total food expenditures and contained over 25,000 line items. Food purchases coded as "other" - food and beverages that do not fit into the 11 coded food categories of interestcomprised the largest share of expenditures at food retailers (66.0\%), followed by vegetables (6.0\%), fruits (5.7\%), sugar sweetened beverages (4.9\%), and savory snacks (4.7\%).
With respect to findings for the number of receipt line items, "other" composed the largest number of line items (59.4\%) followed by vegetables (9.1\%), sugar sweetened beverages (7.2\%), fruits (5.7\%), and savory snacks (5.5\%). "Unsure fruit beverages" (fruit beverages for which it could not be determined whether the beverage was $100 \%$ fruit 
TABLE 3 | Average household food expenditures and receipt line items submitted over a 4-week period by low-income households using a simple annotated receipt method, by food category and store type $(n=260)$.

\begin{tabular}{|c|c|c|}
\hline & $\begin{array}{l}\text { Expenditures } \\
\text { USD }(95 \% \mathrm{Cl})\end{array}$ & $\begin{array}{c}\text { Receipt line items } \\
\text { number }(95 \% \mathrm{Cl})\end{array}$ \\
\hline Total & $272.62(247.13,298.11)$ & $98.8(90.1,107.6)$ \\
\hline \multicolumn{3}{|l|}{ FOOD CATEGORY } \\
\hline Fruits & $15.41(13.05,17.77)$ & $5.6(4.9,6.3)$ \\
\hline Vegetables & $16.34(13.90,17.78)$ & $9.0(7.7,10.2)$ \\
\hline Sweet baked goods & $9.39(7.94,10.85)$ & $3.6(3.1,4.1)$ \\
\hline Candy & $5.70(4.75,6.65)$ & $3.36(2.8,3.9)$ \\
\hline Savory snacks & $12.72(11.15,14.29)$ & $5.4(4.8,6.0)$ \\
\hline Regular, unflavored milk & $8.07(6.59,9.55)$ & $2.5(2.1,2.9)$ \\
\hline Flavored milk & $0.47(0.23,0.71)$ & $0.2(0.1,0.3)$ \\
\hline 100\% Juice & $4.21(3.33,5.10)$ & $1.5(1.2,1.8)$ \\
\hline Sugar-sweetened beverages & $13.45(11.44,15.45)$ & $7.1(6.1,8.2)$ \\
\hline Fruit beverage, unknown type & $1.04(0.62,1.46)$ & $0.4(0.3,0.5)$ \\
\hline Other foods & $180.00(162.52,197.47)$ & $58.7(53.2,64.2)$ \\
\hline Unidentified & $5.81(4.25,7.37)$ & $1.6(1.2,2.0)$ \\
\hline \multicolumn{3}{|l|}{ STORE TYPE } \\
\hline Grocery stores & $169.34(150.37,188.30)$ & $62.4(55.5,69.3)$ \\
\hline Superstores/Mass merchandisers & $115.68(98.89,132.46)$ & $36.9(31.7,42.0)$ \\
\hline Convenience stores/Gas stations & $18.30(15.02,24.57)$ & $11.7(9.7,11.6)$ \\
\hline Drug stores & $10.38(7.82,12.94)$ & $5.0(3.9,6.1)$ \\
\hline
\end{tabular}

juice or a fruit drink that should be classified as a sugar sweetened beverage) comprised $<1$ percent of both the total food spending $(0.4 \%)$ and the proportion of total line items (0.4\%) (Supplemental Table 1). Nearly $60 \%$ of total food retailer expenditures $(\$ 41,826.57)$ was spent in supermarkets/markets, and $\$ 24,985.98$ (35.8\%) was spent in superstores/mass merchandisers/warehouse club stores (Supplemental Table 2).

\section{Unidentified Food Expenditures}

Unidentified food expenditures comprised $2.1 \%$ of total spending and $1.6 \%$ of total line items submitted by 260 households over a 4-week period (Supplemental Table 1). Table 4 presents results from the zero-inflated negative binomial model to evaluate the association between unidentified receipt items and participant characteristic and store type. Drugs stores had a lower rate of unidentified line items compared to supermarkets ( $p=$ 0.04). There were no significant differences in the rate of occurrence of unidentified receipt line items by the participant characteristics examined.

\section{Within- and Between-Household Variation}

Table 5 shows the means, within-household coefficient of variation $\left(\mathrm{CV}_{\mathrm{w}}\right)$, between-household coefficient of variation $\left(\mathrm{CV}_{\mathrm{b}}\right)$, and ratios for weekly household expenditures for total food expenditures and selected food categories. On average, households spent $\$ 85.65$ per week (standard error of the mean [SE] \$5.38) on total food expenditures. Mean household expenditures on fruits and vegetables was $\$ 11.05$ per week (SE
TABLE 4 | Adjusted* incidence rate ratios of unidentified items in receipts submitted over a 4-week baseline period by 260 low-income households using a simple annotated receipt method ( $n=3,530$ food retailer receipts).

Unidentified receipt line items IRR (95\% CI)

\begin{tabular}{|c|c|}
\hline \multicolumn{2}{|l|}{ STORE TYPE } \\
\hline Supermarket (ref) & 1.00 \\
\hline Convenience store/Gas station & $1.03(0.58,1.82)$ \\
\hline Drug store & $0.11(0.01,0.99)$ \\
\hline $\begin{array}{l}\text { Superstore/Mass merchandiser/Warehouse } \\
\text { club store }\end{array}$ & $0.92(0.47,1.80)$ \\
\hline \multicolumn{2}{|l|}{ AGE, YEARS } \\
\hline$<25$ & $1.40(0.67,2.91)$ \\
\hline $25-44$ (ref) & 1.00 \\
\hline $45-64$ & $1.56(0.67,3.66)$ \\
\hline Over 65 & $1.04(1.90,5.70)$ \\
\hline \multicolumn{2}{|l|}{ GENDER } \\
\hline Female (ref) & 1.00 \\
\hline Male & $1.11(0.70,1.82)$ \\
\hline \multicolumn{2}{|l|}{ RACE/ETHNICITY } \\
\hline White, Non-Hispanic (ref) & 1.00 \\
\hline Black, Non-Hispanic & $0.65(0.37,1.13)$ \\
\hline Other, Hispanic & $1.40(0.71,2.62)$ \\
\hline \multicolumn{2}{|l|}{ MARITAL STATUS } \\
\hline Single, never married (ref) & 1.00 \\
\hline Married or partnered & $0.76(0.37,1.13)$ \\
\hline Separated/divorced/widowed & $1.37(0.71,2.62)$ \\
\hline \multicolumn{2}{|l|}{ HOUSEHOLD SIZE } \\
\hline 1 person (ref) & $0.40(0.19,0.84)$ \\
\hline 2 people & $0.68(0.30,1.60)$ \\
\hline 3 people & $0.68(0.41,1.12)$ \\
\hline 4 or more & 1.00 (ref) \\
\hline \multicolumn{2}{|l|}{ EDUCATION LEVEL } \\
\hline High school graduate or less & 1.00 \\
\hline Some college/associates degree (ref) & $0.78(0.50,1.23)$ \\
\hline College graduate or higher & $1.14(0.58,2.23)$ \\
\hline \multicolumn{2}{|l|}{ ANNUAL HOUSEHOLD INCOME } \\
\hline$\$ 14,999$ or less & 1.00 \\
\hline$\$ 15,000-\$ 34,999$ (ref) & $0.79(0.50,1.26)$ \\
\hline$\$ 35,000$ or more & $0.87(0.46,1.64)$ \\
\hline \multicolumn{2}{|l|}{ FOOD SECURITY } \\
\hline Very low (ref) & 1.00 \\
\hline Low & $0.67(0.44,1.04)$ \\
\hline High or marginal & $0.65(0.33,1.27)$ \\
\hline
\end{tabular}

*Model adjusted for the total number of line items per receipt.

\$0.90), with comparable amounts spent on fruits and vegetables individually. Households spent an average of \$7.95 (SE \$0.78) per week on foods high in added sugar, with varying amounts spent on individual food categories. Regardless of food category, $\mathrm{CV}_{\mathrm{w}}$ was larger than $\mathrm{CV}_{\mathrm{b}}$, and both values were higher when evaluating individual food categories for foods high in added sugar. The CV ratio was above 1 for all categories of food, ranging from 1.44 for fruits and vegetables to 6.44 for candy. 
TABLE 5 | Mean weekly expenditures (USD), within-household coefficients of variation $\left(C V_{w}\right)$, between-household coefficients of variation $\left(C V_{b}\right)$, and variance ratios for food expenditures of low-income households using the simple annotated receipt method $(n=260)$.

\begin{tabular}{lcccc}
\hline & $\begin{array}{c}\text { Mean (SE) } \\
\text { Dollars (USD)/week }\end{array}$ & $\mathbf{C V}_{\mathbf{w}}$ & $\mathbf{C V}_{\mathbf{b}}$ & $\begin{array}{c}\text { Variance } \\
\text { Ratio }\end{array}$ \\
\hline Total food expenditures & $85.65(5.38)$ & 70.8 & 49.8 & 2.02 \\
Fruits and vegetables & $11.05(0.90)$ & 85.5 & 71.3 & 1.44 \\
$\quad$ Fruits & $5.67(0.53)$ & 100.5 & 75.6 & 1.77 \\
$\quad$ Vegetables & $5.38(0.52)$ & 104.4 & 81.3 & 1.65 \\
Foods high in added sugar & $7.95(0.78)$ & 105.6 & 79.0 & 1.78 \\
$\quad$ Sugar-sweetened beverages & $3.57(0.45)$ & 138.3 & 95.5 & 2.10 \\
Sweet baked goods & $2.70(0.37)$ & 161.9 & 80.3 & 4.07 \\
Candy & $1.70(0.26)$ & 184.5 & 72.7 & 6.44 \\
\hline
\end{tabular}

$C V_{w}$, Within-household coefficient of variation; $C V_{b}$, Between-household coefficient of variation; Variance ratio, $\sigma_{w}^{2} / \sigma_{b}^{2}=\left(C V_{w} / C V_{b}\right)^{2}$.

Table 6 shows the number of households in a group required to estimate the group mean weekly expenditure with $95 \%$ CIs within 10-50\% deviation of the group's observed mean from the group's usual ("true") mean. To maintain precision of $\pm 20 \%$ of the group's true total food expenditures, at least 72 households are required. Larger group sizes are required to estimate specific food categories, with the highest requirements for evaluating individual categories of food high in added sugar.

Table 7 shows the number of weeks of food expenditure data required to ensure a correlation coefficient, $r$, between observed and true expenditures. As the variance ratio decreased, fewer weeks of observation were needed to rank households by expenditure and distinguish households with low expenditures from those with high expenditures. Assuming $r=0.90$, a minimum of 9 weeks of data are required for total food expenditures, 6 weeks of data for fruits and vegetables, and 8 weeks of data for foods high in added sugar. Compared to evaluating fruits and vegetables as individual food categories, a greater number of weeks are required for evaluating individual categories of food high in added sugar to rank households with a given $r$.

Table 8 shows the number of weeks of food expenditure data required to estimate mean weekly household expenditures with $95 \%$ CIs within 10-50\% deviation from the usual ("true") household expenditure. To maintain precision of $20 \%$ within the household's true expenditures, 48 weeks are required to estimate total food expenditures with 95\% CIs. Greater number of replicate weeks of data are required to estimate individual food categories, with the highest number of weeks for categories of foods high in added sugar.

\section{DISCUSSION}

This paper describes and evaluates a simple annotated receipt method for assessing household food purchasing. Results show that the method can capture food purchasing information for
TABLE 6 | Number of households in a group needed to estimate weekly expenditures with 95\% Cls within 10-50\% deviation of the observed group mean from the group's usual ("true") mean using a single week of expenditure data.

\begin{tabular}{lccccc}
\hline & \multicolumn{5}{c}{ Specified \% of true mean } \\
\cline { 2 - 6 } & $\mathbf{1 0 \%}$ & $\mathbf{2 0 \%}$ & $\mathbf{3 0 \%}$ & $\mathbf{4 0 \%}$ & $\mathbf{5 0 \%}$ \\
\hline Total food expenditures & 288 & 72 & 32 & 18 & 12 \\
Fruits and vegetables & 477 & 119 & 53 & 30 & 19 \\
$\quad$ Fruits & 609 & 152 & 68 & 38 & 24 \\
Vegetables & 674 & 168 & 75 & 42 & 27 \\
Foods high in added sugar & 669 & 167 & 74 & 42 & 27 \\
$\quad$ Sugar-sweetened beverages & 1087 & 272 & 121 & 68 & 43 \\
Sweet baked goods & 1256 & 314 & 140 & 79 & 50 \\
Candy & 1514 & 379 & 168 & 95 & 61 \\
\hline
\end{tabular}

TABLE 7 | Number of weeks of data needed to ensure a given correlation coefficient, $r$, between observed and usual ("true") weekly household expenditures.

\begin{tabular}{lccccc}
\hline & \multicolumn{5}{c}{$\boldsymbol{r}$-value } \\
\cline { 2 - 6 } & $\mathbf{0 . 7 5}$ & $\mathbf{0 . 8 0}$ & $\mathbf{0 . 8 5}$ & $\mathbf{0 . 9 0}$ & $\mathbf{0 . 9 5}$ \\
\hline Total food expenditures & 3 & 4 & 5 & 9 & 19 \\
Fruits and vegetables & 2 & 3 & 4 & 6 & 13 \\
$\quad$ Fruits & 2 & 3 & 5 & 8 & 16 \\
Vegetables & 2 & 3 & 4 & 7 & 15 \\
Foods high in added sugar & 2 & 3 & 5 & 8 & 17 \\
Sugar-sweetened beverages & 3 & 4 & 5 & 9 & 19 \\
Sweet baked goods & 5 & 7 & 11 & 17 & 38 \\
Candy & 8 & 11 & 17 & 27 & 60 \\
\hline
\end{tabular}

TABLE 8 | Number of weeks of data needed to estimate mean household expenditures with 95\% Cls within 10-50\% of the usual ("true") household mean.

\begin{tabular}{lccccc}
\hline & \multicolumn{5}{c}{ Specified \% of usual (true) mean } \\
\cline { 2 - 6 } & $\mathbf{1 0 \%}$ & $\mathbf{2 0 \%}$ & $\mathbf{3 0 \%}$ & $\mathbf{4 0 \%}$ & $\mathbf{5 0 \%}$ \\
\hline Total food expenditures & 192 & 48 & 21 & 12 & 8 \\
Fruits and vegetables & 281 & 70 & 31 & 18 & 11 \\
Fruits & 388 & 97 & 43 & 24 & 16 \\
Vegetables & 419 & 105 & 47 & 26 & 17 \\
Foods high in added sugar & 428 & 107 & 48 & 27 & 17 \\
$\quad$ Sugar-sweetened beverages & 734 & 184 & 82 & 46 & 29 \\
Sweet baked goods & 1006 & 252 & 112 & 63 & 40 \\
Candy & 1308 & 327 & 145 & 82 & 52 \\
\hline
\end{tabular}

various food categories in a variety of store types, and may be a feasible tool for use among diverse, low-income populations.

Most food items on the receipts could be coded into one of the 11 food categories of interest in the study. Only $1.6 \%$ of line items-comprising $2.1 \%$ of total spending-could not be categorized because of insufficient detail. Importantly, unidentified line items did not vary by demographic characteristics, which suggests that the tool is applicable to 
diverse, low-income populations. Compared to supermarkets, drug stores had a lower rate of unidentified items. This may be because drugs stores tend to sell less produce, fresh meats, and bulk items, which often lack detail on receipts and require less annotation by the participant.

Findings also suggest that the simple annotated receipt method may be adapted for specific research questions. While the majority of food items were coded as "other," this is a result of a priori food category definitions outlined in the study protocol. The experimental trial for which this method was developed assessed policy changes to SNAP. As a result, the focus was on policy-specific food categories-specifically, fruits, vegetables, sweet baked goods, sugary sweetened beverages, and candies. The "other" category captured foods that were of lesser interest to the study aims, such as diet sodas and water. However, this category is adaptable to various study-specific questions. For example, sugar-sweetened beverages (SSBs) and fruit juices were of interest in the study. To ensure comprehensive and precise evaluation of beverage expenditures, multiple categories of beverages were specified, including a "fruit beverage, unknown type" category for fruit beverages that could not be identified as either $100 \%$ fruit juice or a sugar-sweetened fruit drink. Items labeled "fruit beverage, unknown type" comprised only $0.4 \%$ of receipt line items in comparison to $7.2 \%$ of line items for SSB and $1.5 \%$ of line items for fruit juices, suggesting that the present method can differentiate food and beverage categories as required by studyspecific aims. Researchers interested in capturing different food or beverage categories can therefore adapt the method to studyspecific needs using different coding protocols (e.g., "diet sodas" were included in the "other" category in the present study, but can be coded).

To our knowledge, this is the first study to apply established methods of evaluating within- and between-individual variations to a food expenditure assessment tool (27-29). The results have implications for the design of studies evaluating household food expenditures in lower-income households. $\mathrm{CV}_{\mathrm{w}}$ and $\mathrm{CV}_{\mathrm{b}}$ values were lowest for total food expenditures and largest for individual categories of foods high in added sugar. Larger $\mathrm{CV}_{\mathrm{w}}$ values for foods high in added sugar values had the greatest impact on the number of replicate weeks required to assess a household's usual food expenditures. For example, candy had the highest $\mathrm{CV}_{\mathrm{w}}$ value of the food categories evaluated, requiring 52 to 1,307 weeks to estimate the household mean weekly expenditure within $10-50 \%$ deviation of the true values. Future researchers should consider alternative or additional tools to evaluate expenditures of foods such as SSBs, candies, and sweet baked goods that are highly variably purchased week to week by households.

Our findings also suggest that the simplified annotated food receipt method is most appropriate for comparing mean expenditures of different study groups or ranking household expenditures (e.g., into quartiles). For example, a group size of at least 119 households is required to estimate the mean group expenditure on fruits and vegetables within $20 \%$ of the true mean. Similarly, at least 6 weeks of data are required to rank households by weekly fruit and vegetable expenditure level with a precision of $r=0.90$.

\section{Strengths and Limitations}

Food purchasing behavior is strongly patterned by socioeconomic status $(7,8)$, but few food receipt methods have been evaluated in low-income households (12). This study addresses the need for feasible methods to evaluate food purchasing. Importantly, this novel method was evaluated in a sample of diverse, low-income households. This study also has a relatively large sample size and prolonged duration of receipt collection for evaluation of a measurement method.

There are several limitations worth noting. This study did not assess the completeness of receipt submission, the accuracy of receipt annotation, or the reliability of coding. It is possible that receipts were not submitted for some food purchases, resulting incomplete assessment of food purchasing. Future evaluations of this methodology should evaluate completeness of receipt submission and evaluate interrater reliability of receipt coding. Furthermore, this receipt method does not provide information on food quantities. Expenditure data may suffice if change in food purchasing is the primary outcome of interest (e.g., to evaluate whether an intervention decreases purchasing of SSBs). Previous studies also suggest that food expenditure data may be a reasonable approximation of intake $(17,19,21)$. Evaluating the association of expenditure data with food quantities and dietary intake is an area for further method development. The present analyses also relies on a sample of lower-income households in one metropolitan area. The levels of variation in food expenditures may differ for other population groups and requires further research.

Finally, the present method was not directly compared to other receipt methods. A qualitative review of previously published studies shows that results are somewhat comparable. This suggests that the present method may be able to capture details similar to previous receipt methods-while potentially reducing the burden for participants (compared to the annotated receipt method) and minimizing the number of unidentified food expenditures (compared to the receipt collection method). A study using the annotated receipt collection method, which requires transcription of all receipt information, collected an average of 3.1 receipts from food retailers per household per week (24). This is comparable to an average of 3.3 receipts per household per week in the present study. The annotated receipt method also yielded an average of 25.8 line items per household per week for both food retailers and restaurant receipts (24)-compared to 24.7 line items per household per week in the present study, which included only food retailers. Results for specific beverage categories across receipt methods also suggests similarities. Sugar-sweetened beverages accounted for $9.1 \%$ of all line items using the annotated receipt method, compared to $7.2 \%$ in the present study (24). In a study using the receipt collection method-which involves neither annotation or transcription- $-100 \%$ fruit juices comprised $1.6 \%$ of total grocery expenditures, similar to $1.6 \%$ of total expenditures in the present study (22). Importantly, the present method may have a lower rate of "missing/unclassified" items compared 
to the receipt collection method, which was previously reported as having $7.7 \%$ "missing classified/unclassified" expenditures (22).

However, it is worth noting that the annotated receipt method and receipt collection methods discussed above were deployed in different populations and studies. The annotated receipt method followed 90 participants who were predominantly white women in Minneapolis, Minnesota, for 4 weeks. In contrast, the receipt collection method was used for a sample of 107 diverse, low-income households in Houston, Texas over a 6-weeks period. The present study is specific to ethnically and racially diverse households in the Minneapolis-St. Paul, Minnesota, metropolitan area. Future studies are needed to formally compare different methods.

\section{CONCLUSIONS}

The simple annotated food purchase receipt method is a promising approach for assessing food purchasing behavior. Our findings suggest that this method is able to capture a wide range of food purchasing information from a variety of store types. Unidentified items were limited and did not vary by participant characteristic or stores, suggesting that the present method is broadly applicable among diverse, low-income households. This paper is also the first to quantify withinand between-household variation in food expenditures using a receipt method, which is crucial information for determining sample sizes, estimating data collection periods, and interpreting findings. Research is needed to further evaluate the method and compare it to alternative receipt methods to assess food purchasing behavior.

\section{REFERENCES}

1. Ammerman AS, Lindquist $\mathrm{CH}$, Lohr $\mathrm{KN}$, Hersey J, Achterberg C, BaraNowski T, et al. The efficacy of behavioral interventions to modify dietary fat and fruit and vegetable intake: a review of the evidence. Med Consult Prev Med. (2002) 35:25-41. doi: 10.1006/pmed.2002.1028

2. Seymour JD, Lazarus Yaroch A, Serdula M, Blanck HM, Khan LK. Impact of nutrition environmental interventions on pointof-purchase behavior in adults: a review. Prev Med. (2004) 39(Suppl.2):S108-36. doi: 10.1016/j.ypmed.2004.04.002

3. Epstein LH, Jankowiak N, Nederkoorn C, Raynor HA, French SA, Finkelstein E. Experimental research on the relation between food price changes and food-purchasing patterns: a targeted review. Am J Clin Nutr. (2012) 95:789809. doi: 10.3945/ajen.111.024380

4. Gittelsohn J, Trude ACB, Kim H. Pricing strategies to encourage availability, purchase, and consumption of healthy foods and beverages: a systematic review. Prev Chronic Dis. (2017) 14:170213. doi: 10.5888/pcd14.170213

5. Appelhans BM, French SA, Tangney CC, Powell LM, Wang Y. To what extent do food purchases reflect shoppers' diet quality and nutrient intake? Int $J$ Behav Nutr Phys Act. (2017) 14:46. doi: 10.1186/s12966-017-0502-2

6. Darmon N, Drewnowski A. Contribution of food prices and diet cost to socioeconomic disparities in diet quality and health: a systematic review and analysis. Nutr Rev. (2015) 73:643-60. doi: 10.1093/nutrit/nuv027

7. Darmon N, Drewnowski A. Does social class predict diet quality? Am J Clin Nutr. (2008) 87:1107-17. doi: 10.1093/ajcn/87.5.1107

8. Appelhans BM, Milliron BJ, Woolf K, Johnson TJ, Pagoto SL, Schneider KL, et al. Socioeconomic status, energy cost, and nutrient

\section{DATA AVAILABILITY STATEMENT}

The raw data supporting the conclusions of this article will be made available by the authors, without undue reservation.

\section{ETHICS STATEMENT}

The studies involving human participants were reviewed and approved by The University of Minnesota Institutional Review Board. The patients/participants provided their written informed consent to participate in this study.

\section{AUTHOR CONTRIBUTIONS}

SV performed statistical analyses. SV and LH wrote the first draft of the manuscript. All authors read and approved the final manuscript. All authors contributed to the article and approved the submitted version.

\section{FUNDING}

The project described was supported by Award Numbers R01DK098152 and T32DK083250 from the National Institute of Diabetes and Digestive and Kidney Diseases at the Division of Epidemiology \& Community Health, School of Public Health at the University of Minnesota.

\section{SUPPLEMENTARY MATERIAL}

The Supplementary Material for this article can be found online at: https://www.frontiersin.org/articles/10.3389/fnut.2020. 582999/full\#supplementary-material

content of supermarket food purchases. Am J Prev Med. (2012) 42:398-402. doi: 10.1016/j.amepre.2011.12.007

9. Patterson RE, Kristal AR, Shannon J, Hunt JR, White E. Using a brief household food inventory as an environmental indicator of individual dietary practices. Am J Public Health. (1997) 87:272-5. doi: 10.2105/AJPH.87.2.272

10. Miller C, Edwards L. Development and validation of a shelf inventory to evaluate household food purchases among older adults with diabetes mellitus. J Nutr Educ Behav. (2002) 34:261-7. doi: 10.1016/S1499-4046(06)60104-8

11. Marsh T, Cullen KW, Baranowski T. Validation of a fruit, juice, and vegetable availability questionnaire. J Nutr Educ Behav. (2003) 35:937. doi: 10.1016/S1499-4046(06)60045-6

12. French SA, Shimotsu ST, Wall M, Gerlach AF. Capturing the spectrum of household food and beverage purchasing behavior: a review. J Am Diet Assoc. (2008) 108:2051-8. doi: 10.1016/j.jada.2008.09.001

13. Baxter JS, Graves KL, Mullis RM, Potter JD. Experiences in using computerized sales data to evaluate a nutrition intervention program. J Nutr Educ Behav. (1996) 28:164-7. doi: 10.1016/S0022-3182(96) 70052-3

14. Weinstein JL, Phillips V, MacLeod E, Arsenault M, Ferris AM. A universal product code scanner is a feasible method of measuring household food inventory and food use patterns in low-income families. J Am Diet Assoc. (2006) 106:443-5. doi: 10.1016/j.jada.2005.12.004

15. Brimblecombe J, Liddle R, O'Dea K. Use of point-of-sale data to assess food and nutrient quality in remote stores. Public Health Nutr. (2013) 16:115967. doi: 10.1017/S1368980012004284

16. Timmins KA, Morris MA, Hulme C, Edwards KL, Clarke GP, Cade JE. Comparability of methods assigning monetary costs to diets: derivation 
from household till receipts versus cost database estimation using 4-day food diaries. Eur J Clin Nutr. (2013) 67:1072-6. doi: 10.1038/ejen.20 13.157

17. Ransley JK, Donnelly JK, Khara TN, Botham H, Arnot H, Greenwood DC, et al. The use of supermarket till receipts to determine the fat and energy intake in a UK population. Public Health Nutr. (2001) 4:127986. doi: 10.1079/PHN2001171

18. Ricciuto L, Tarasuk V, Yatchew A. Socio-demographic influences on food purchasing among canadian households. Eur J Clin Nutr. (2006) 60:77890. doi: $10.1038 /$ sj.ejcn. 1602382

19. Lambe J, Kearney J, Becker W, Hulshof K, Dunne a, Gibney MJ. Predicting percentage of individuals consuming foods from percentage of households purchasing foods to improve the use of household budget surveys in estimating food chemical intakes. Public Health Nutr. (1998) 1:23947. doi: 10.1079/PHN19980040

20. Becker W. Comparability of household and individual food consumption data-evidence from Sweden. Public Health Nutr. (2001) 4:1177-82. doi: 10.1079/PHN2001197

21. Sekula W, Nelson M, Figurska K, Oltarzewski M, Weisell R, Szponar L. Comparison between household budget survey and 24-hour recall data in a nationally representative sample of Polish households. Public Health Nutr. (2005) 8:430-9. doi: 10.1079/PHN2004695

22. Cullen K, Baranowski T, Watson K, Nicklas T, Fisher J, O’Donnell $\mathrm{S}$, et al. Food category purchases vary by household education and race/ethnicity: results from grocery receipts. J Am Diet Assoc. (2007) 107:1747-52. doi: 10.1016/j.jada.2007.07.007

23. DeWalt KM, D'Angelo S, McFadden M, Danner FW, Noland M, Kotchen JM. The use of itemized register tapes for analysis of household food acquisition patterns prompted by children. J Am Diet Assoc. (1990) 90:559-62.

24. French S, Wall M, Mitchell N, Shimotsu S, Welsh E. Annotated receipts capture household food purchases from a broad range of sources. Int J Behav Nutr Phys Act. (2009) 6:37. doi: 10.1186/1479-5868-6-37

25. French SA, Wall M, Mitchell NR. Household income differences in food sources and food items purchased. Int J Behav Nutr Phys Act. (2010) 7:77. doi: 10.1186/1479-5868-7-77

26. Harnack L, Oakes J, Elbel B, Beatty T, Rydell S, French S. Effects of subsidies and prohibitions on nutrition in a food benefit program: a randomized clinical trial. JAMA Intern Med. (2016) 176:1610-8. doi: 10.1001/jamainternmed.2016.5633
27. Nelson M, Black AE, Morris JA, Cole TJ. Between- and within-subject variation in nutrient intake from infancy to old age: estimating the number of days required to rank dietary intakes with desired precision. Am J Clin Nutr. (1989) 50:155-67. doi: 10.1093/ajcn/50.1.155

28. Willet WC. Nutrition Epidemiology. 3rd Edition. New York, NY: Oxford University Press (2013).

29. Beaton GH, Milner J, Corey P, McGuire V, Cousins M, Stewart E, et al. Sources of variance of 24-hour dietary recall data: implications for nutrition study designing and interpretation. Am J Clin Nutr. (1979) 32:254659. doi: $10.1093 / \mathrm{ajcn} / 32.12 .2546$

30. Rydell SA, Turner RM, Lasswell TA, French SA, Oakes JM, Elbel $B$, et al. Participant satisfaction with a food benefit program with restrictions and incentives. J Acad Nutr Diet. (2017) 118:294-300. doi: 10.1016/j.jand.2017.08.010

31. French SA, Rydell SA, Mitchell NR, Michael Oakes J, Elbel B, Harnack L. Financial incentives and purchase restrictions in a food benefit program affect the types of foods and beverages purchased: results from a randomized trial. Int J Behav Nutr Phys Act. (2017) 14:127. doi: 10.1186/s12966-0170585-9

32. Service UER. US Household Food Security Survey Module: Six-Item Short Form. (2012). Available from: http://www.ers.usda.gov/topics/food-nutritionassistance/food-security-in-the-us/survey-tools.aspx (accessed December 23, 2015).

33. Liu K, Stamler J, Dyer A, McKeever J, McKeever P. Statistical methods to assess and minimize the role of intra-individual variability in obscuring the relationship between dietary lipids and serum cholesterol. J Chronic Dis. (1978) 31:399-418. doi: 10.1016/0021-9681(78)90004-8

Conflict of Interest: The authors declare that the research was conducted in the absence of any commercial or financial relationships that could be construed as a potential conflict of interest.

Copyright ( 2020 Valluri, French, Elbel, Oakes, Rydell and Harnack. This is an open-access article distributed under the terms of the Creative Commons Attribution License (CC BY). The use, distribution or reproduction in other forums is permitted, provided the original author(s) and the copyright owner(s) are credited and that the original publication in this journal is cited, in accordance with accepted academic practice. No use, distribution or reproduction is permitted which does not comply with these terms. 